\title{
An azide and acetylene free synthesis of 1-substituted 1,2,3-triazoles
}

\author{
Sarah J.M. Patterson ${ }^{a}$, Peter R. Clark ${ }^{\mathrm{a}, \mathrm{b}, \Uparrow}$, Glynn D. Williams ${ }^{\mathrm{a}, 1}$, Nicholas C.O. Tomkinson ${ }^{\mathrm{b}}$ \\ ${ }^{a}$ Chemical Development, GlaxoSmithKline, Gunnels Wood Road, Stevenage SG1 2NY, United Kingdom \\ ${ }^{\mathrm{b}}$ Department of Pure and Applied Chemistry, University of Strathclyde, 295 Cathedral Street, Glasgow G1 1XL, United Kingdom
}

\begin{tabular}{|c|c|}
\hline article info & abstract \\
\hline Article history: & This paper details a simple and efficient 3-component synthesis of 1-substituted 1,2,3-triazoles using a primary amine, 2,2- \\
\hline Received 7 July 2020 & dimethoxyacetaldehyde and tosylhydrazide. The reaction proceeds in good to excel- lent yields using either aliphatic or \\
\hline Revised 17 September 2020 & aromatic amine substrates and is tolerant of a wide range of func- tional groups including electron-rich and \\
\hline Accepted 21 September 2020 & deficient aryl groups, terminal alkynes, ketones and highly \\
\hline Available online $\mathrm{xxxx}$ & sterically encumbered amines. \\
\hline
\end{tabular}

Keywords:

1,2,3-Triazole

Dimethoxyacetaldehyde

Tosyl hydrazide

Heterocyclisation

Azide-free

Acetylene-free

1-Substituted triazoles are prevalent bioactive substrates, exemplified by their occurrence in important pharmaceutical com- pounds. Tazobactam 1 is a beta-lactamase inhibitor used to treat a variety of bacterial infections [1] and IMG-7289 2 is an irreversible LSD1 inhibitor currently in Phase 2b clinical trials for the treatment of patients with myelofibrosis and myeloid leukaemia (Fig. 1) [2]. The presence of $\mathrm{N}$-alkyl and $\mathrm{N}$-aryl 1,2,3-triazoles in pharmaceutical compounds suggests that the development of new, efficient methodologies to synthesise these functionalities will be of great value to chemical industries.

A direct method for the synthesis of 1-substituted triazoles is the copper(I) azide-alkyne cycloaddition reaction (CuAAC) with an organic azide 3 and acetylene gas (Fig. 2a) [3,4]. Acetylene is a flammable and explosive gas and as such, powerful engineering solutions have been developed to overcome the safety hazards associated with this methodology [5]. An additional challenge with this approach is the fact that acetylene can react with a copper(I) source to produce the heat and shock-sensitive explosive copper acetylide [6]. Therefore, it is unsurprising that safer, indirect alter- natives for this transformation have been developed. The protecting groups utilised are often $\mathrm{C}\left(\mathrm{CH}_{3}\right)_{2} \mathrm{OH}$, trimethylsilyl- and carboxyl-, as well as the inorganic source of acetylene, calcium car- bide. These species have proven to be valuable synthetic precursors

\footnotetext{
E-mail address: peter.r.clark@gsk.com (P.R. Clark).

${ }^{1}$ Current address: API Chemistry, Aptuit, 111 Innovation Dr, Milton, Abingdon OX14 4RZ, United Kingdom.
}

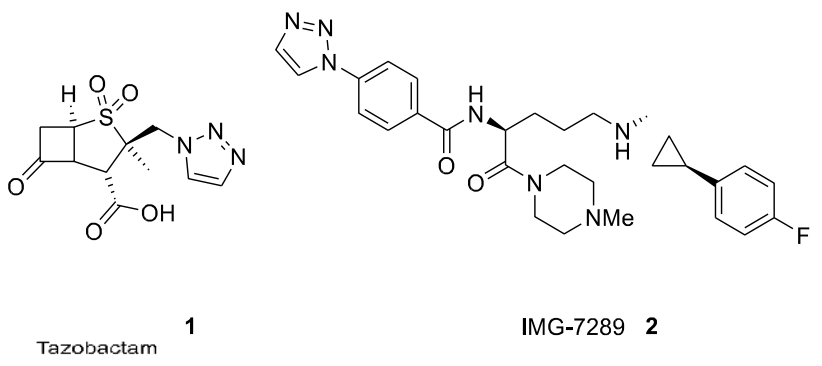

Fig. 1. Examples of biologically active 1,2,3-triazoles.

to access triazole products (Fig. 2a) [7-10]. Whilst these are easier to handle than acetylene, the products require an extra syn- thetic step to remove the handle, increasing the length of the syn- thesis and inevitably resulting in a loss of yield. To this end, Moses recently presented a traceless alternative using ethenesulfonyl flu- oride (4, ESF) to give triazole products which could be isolated without the need for protecting groups (Fig. 2b) [11]. Whilst the growing popularity of sulfur-fluoride exchange (SuFEx) reagents and the valuable transformations these reagents offer is undeniable, the liberation of noxious gases $\left(\mathrm{SO}_{2}\right)$ and poor cost and atom efficiency render these reactions less desirable to large-scale synthetic procedures. Moreover, the use of organic azides remains essential for each of these procedures. These species often require preparation and the high energetics associated with azides would necessitate significant process understanding on a larger scale.

An alternative to the use of azides is to use the preformed parent heterocycle, 1,2,3-triazole (5), to access 1-substituted triazoles. 
a) Azlde-alkyne cycloaddltion

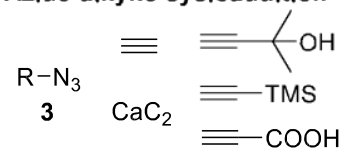

Use of azlde reagents

Transition metal required

C) Alklyation or cross coupling<smiles>[X][R]</smiles>

Regloselectivity concerns Transitlon metal required
$5 \quad \mathrm{X}=\mathrm{Br}$, I b) Azlde and ESF

$\mathrm{R}-\mathrm{N}_{3}$

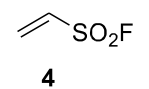

Llberates noxlous gases

Use of azlde reagents

$$
\text { d) Sakal reactlon }
$$

Two-step process Chlorlnated reagent

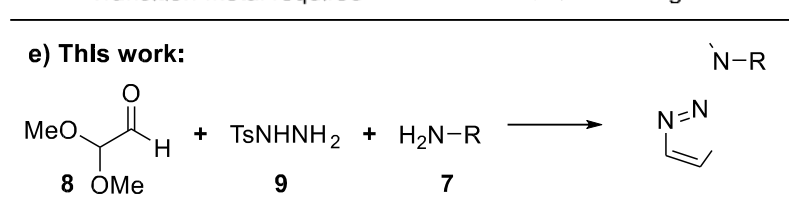

Fig. 2. Common methods for 1-substituted triazole synthesis.

This species is known to participate in $\mathrm{S}_{\mathrm{N}} 2$ reactions or metal catalysed crosscouplings (Fig. 2c) $[12,13]$. Whilst effective, these reactions tend to offer poor regioselectivity, leading to mixtures of 1- substituted and 2-substituted products that can be difficult to separate.

Harada and Singh have both reported an adaption of the Sakai reaction $[14,15]$ showing that dichlorohydrazone 6 can react with a primary amine 7 to furnish 1-substituted triazoles (Fig. 2d) $[16,17]$. However, the use of halogenated reagents and the requirement to prepare and isolate a potentially hazardous hydrazone intermediate (6) is undesirable. There remains an unmet challenge for the direct, one-pot synthesis of 1-substituted triazoles from a primary amine.

Recently, both ourselves and a group from Pfizer simultaneously reported that a-ketoacetals could be used as effective triazole precursors through a one-pot, three-component synthesis leading to a simple method for the preparation of 4-, 1,4-, 1,5-

and 1,4,5-substituted triazole products.[18,19] We believed that this method would be applicable to a novel procedure to access

1-substituted 1,2,3-triazoles. Within this work we describe our findings which show the use of readily available 2,2-dimethoxyacetaldehyde 8 as a precursor to this important heterocycle through the reaction with p-toluene sulfonylhydrazide (9) and a primary amine (7, Fig. 2e).

Condensation of p-toluene sulfonylhydrazide 9 with an aqueous solution of dimethoxyacetaldehyde 8 proceeded smoothly in methanol to give the intermediate hydrazone 10 after 2 h.[20] Addition of benzylamine (11) directly to the reaction mixture and heating the resulting solution in a sealed tube at $75 \mathrm{C}$ for

$16 \mathrm{~h}$ gave 65\% N-benzyltriazole 12 (Entry 1, Table 1). Surprisingly, in contrast to literature observations [18], addition of triethylamine (1.1 equiv) lowered the yield of 12 to $57 \%$ (Entry 2). Examination of the literature surrounding the Sakai reaction suggests that chlorovinyldiazene 13 is a potential intermediate in the trans- formation [21]. The mass of the analogous enol ether diazene inter- mediate 14 was observed as a fragment ion of hydrazone 10 in an LCMS experiment $\left(\mathrm{m} / \mathrm{z}=241.1\right.$ in the MS ES $\left.{ }^{+}\right)$. Despite being unable to isolate a clean sample of compound 14 , the presence of a fragment ion consistent in mass with this species $(\mathrm{m} / \mathrm{z}=241)$ suggests that it could play an important role in the reaction mechanism. To promote collapse of acetal 10 to enol ether 14, Entry 3 details the result of an experiment performed in the presence of 1 equivalent of acetic acid, which led to a $78 \%$ solution yield of the triazole 12 . The stronger acid, methanesulfonic acid, almost entirely shut down the desired reaction pathway ( $2 \% 12,16 \mathrm{~h}$, Entry 4) suggesting the process is $\mathrm{pH}$ sensitive. This remains in contrast to our previous work which showed that the yield of the desired triazole product proved to be $\mathrm{pH}$ independent [18]. 0.1 equivalents of acetic acid resulted in only a slight decrease in yield of the desired triazole ( $72 \%$ yield Entry 5), whilst increasing the acetic acid loading to 5 equivalents did not prove beneficial (Entry 6, 74\%). Finally, we observed that lower temperatures resulted in lower yields of triazole 12 after prolonged reaction times (54\% at 30 C, 72 h, Entry 7) [22]. With these observations, the conditions shown in Entry 3 were scaled up and we isolated $76 \%$ of triazole 12 .

We next turned our attention to aniline nucleophiles, speculating that less basic primary amines would prove to be effective substrates under the acidic reaction conditions (Scheme 1). Using aniline (15) as the coupling partner gave an excellent yield of 1-phenyl triazole (97\% yield). Further exploration of anilines revealed that halogenated substrates (fluoro-, chloro-,

Table 1

Optimisation of the presented transformation.

\begin{tabular}{|c|c|c|c|c|}
\hline Entry & Temperature ( C) & Additive(equiv) & Time (h) & 12 yield $^{[\mathrm{a}]}$ \\
\hline 1 & 75 & none & 16 & $65^{[\mathrm{b}]}$ \\
\hline 2 & 75 & $\mathrm{Et}_{3} \mathrm{~N}(1.1)$ & 16 & $57^{[\mathrm{b}]}$ \\
\hline 3 & 75 & $\mathrm{AcOH}(1.0)$ & 16 & $78^{[\mathrm{b}]}(76)$ \\
\hline 4 & 75 & $\mathrm{MsOH}(1.0)$ & 16 & 2 \\
\hline 5 & 75 & $\mathrm{AcOH}(0.1)$ & 16 & 72 \\
\hline 6 & 75 & $\mathrm{AcOH}(5.0)$ & 16 & 74 \\
\hline 7 & 30 & $\mathrm{AcOH}(1.0)$ & 72 & 54 \\
\hline
\end{tabular}
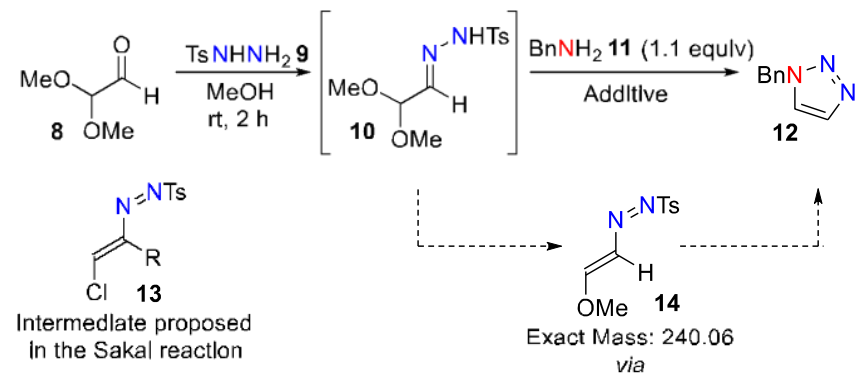

[a] solution yield calculated using 1,3,5-trimethoxybenzene by ${ }^{1} \mathrm{H}$ NMR spectroscopy. [b] solution yield calculated as an average of 3 experiments. The yield in parenthesis was the isolated yield of one experiment after chromatographic purification. 


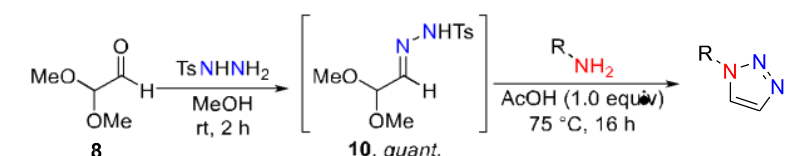
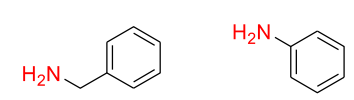<smiles>Nc1ccc(F)cc1</smiles><smiles>Nc1ccc(Cl)cc1</smiles>

$1176 \%$

$$
1597 \%
$$

$1682 \%$

$1775 \%$<smiles>Nc1ccc(Br)cc1</smiles><smiles>Nc1ccc(I)cc1</smiles><smiles>Cc1ccc(F)c(N)c1</smiles><smiles>COc1ccc(N)cc1</smiles>

$1875 \%$

$$
1978 \%
$$

$2090 \%$

$$
2190 \%
$$<smiles>CNc1ccc(N)cc1</smiles><smiles>CC(=O)c1ccc(N)cc1</smiles><smiles>CC(=O)c1ccc(N)cc1</smiles><smiles>Nc1ccc([N+](=O)[O-])cc1</smiles>
$2581 \%$ $2278 \%$ $2395 \%$ $2498 \%$<smiles>Nc1ccccc1O</smiles><smiles>Nc1ccccn1</smiles><smiles>Nc1cccnc1</smiles>

$2682 \%$
$2784 \%$
$2838 \%$

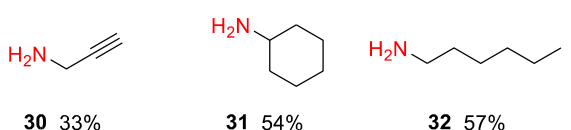

$3033 \%$

$3154 \%$

$3257 \%$
Scheme 1. Scope of the developed method, showing the amine starting materials utilised. Percentages shown correspond to the isolated yield of the corresponding triazole product after column chromatography.

bromo- and iodo-anilines) gave the triazole products 16-19 (71$82 \%$ ) and the trisubstituted aniline substrate 20 gave the triazole product in 90\% yield. Both electron-rich (methoxy 21 90\%, dimethylamino 22 $78 \%$ ) and electron-deficient systems (acetophenone 23 95\%, methyl ester $2498 \%$, nitro $2581 \%$ yield) were also tolerated within the transformation. Sterically encumbered 2,6- dimethylaniline 26 provided access to the triazole product in $82 \%$ yield showing a high level of steric tolerance within the amine partner. Aminophenol 27 afforded an $84 \%$ yield of the triazole pro- duct in which the phenol did not require protection. Aminopyridi- nes 28 and 29 also proved effective within the transformation providing the expected products in $38 \%$ and $64 \%$ yield respectively. Next, we explored some simple aliphatic amines including propargylamine 30 (33\%), cyclohexylamine $31(54 \%)$ and hexylamine $32(57 \%)$ which all provided the expected triazole products [23]. Further optimisation of the standard reaction conditions should allow for further development of the scope of this transformation.

As an exemplification of this method, we isolated $13.35 \mathrm{~g}$ of the product derived from methyl 4-aminobenzoate 24 in $85 \%$ yield after a simple precipitative workup (Scheme 2). This triazole pro- duct can then be used to prepare the irreversible LSD1 inhibitor, IMG-7289 (2) in 6 steps using known literature transformations [24]. The high-yielding nature of the transformation highlights the practical utility of this method to synthesise biologically active

1-substituted triazoles on a preparative scale.

A potential mechanism for this 3-component coupling procedure is outlined in Scheme 3. Hydrazone 10 can eliminate an equivalent of methanol to form enoldiazene intermediate 14 . This species can undergo a 1,4addition with the primary amine, analogous to the Sakai reaction forming hemiaminal intermediate $33[14,15,20]$. This species is then primed to lose a second equivalent of methanol leading to enaminediazene 34 . Under the acidic reaction conditions, protonation of this species can be invoked,
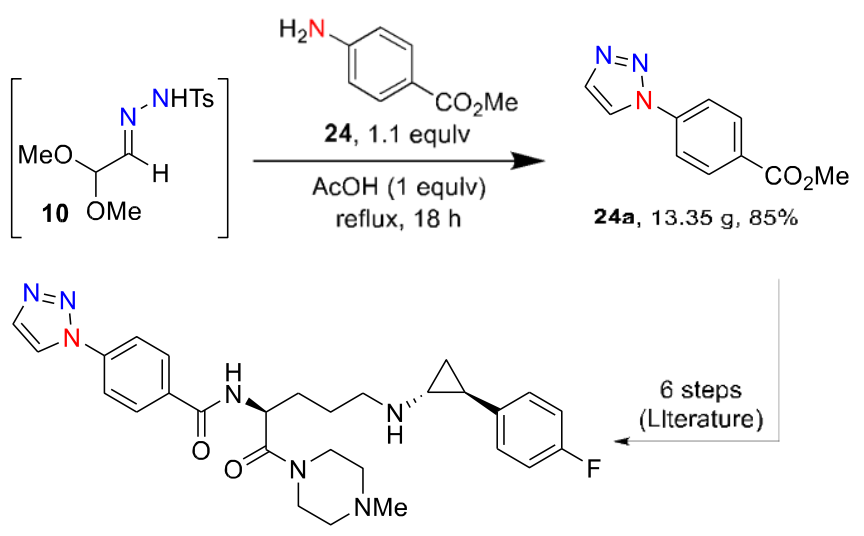

IMG-7289 2

Scheme 2. Triazole formation on a multi-gram scale.

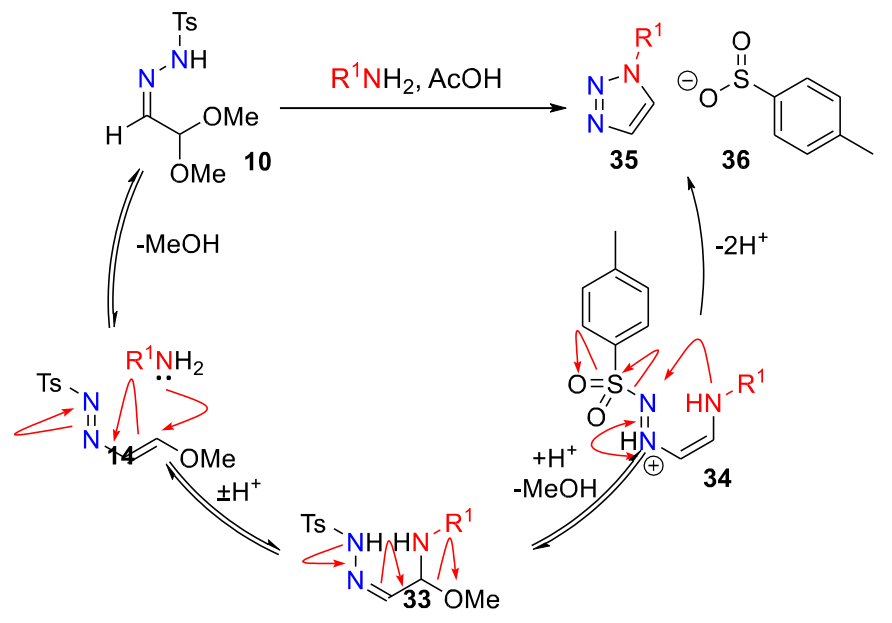

Scheme 3. A proposed mechanism for the transformation.

enabling an addition-elimination sequence to form the triazole product 35 after elimination of p-toluene sulfinate (36) [25].

In conclusion, an operationally simple azide, halogen and acetylene free synthesis of 1-substituted-1,2,3-triazoles has been developed. The reaction involves the condensation of 2,2-dimethoxyacetaldehyde 8 with p-toluene sulfonylhydrazide 9 and reaction of the resultant hydrazone with a primary amine 7 under mildly acidic conditions. The transformation tolerates a wide range of functional groups, including alkynes, ketones, alcohols, esters and halides. The developed method presents a regiospecific alternative to literature processes that avoids the use of both azides and acetylene derivatives, as well as providing a transitionmetal free route to these valuable compounds. This important new method will therefore have applications in the synthetic com- munity when the use of azides and acetylene are discouraged.

\section{Declaration of Competing Interest}

The authors declare that they have no known competing financial interests or personal relationships that could have appeared to influence the work reported in this paper. 


\section{Acknowledgements}

The authors thank GlaxoSmithKline for funding and chemical resources (PRC, SJMP) and the EPSRC for funding via Prosperity Partnership $\mathrm{EP} / \mathrm{S} 035990 / 1$. The authors thank J. Hayes for his early work and for helpful discussions during the preparation of this manuscript.

\section{Appendix A. Supplementary data}

Supplementary data to this article can be found online at https://doi.org/10.1016/j.tetlet.2020.152483.

\section{References}

[1] Y. Yang, B.A. Rasmussen, D.M. Shlaes, Pharmacol. Ther. 83 (1999) 141-151. [2] K. Pettit, N. Curtin, M. Tartaczuch, J. Shortt, J. Watts, W. Stevenson, A. Gerds, K. Burbury, A. Yacoub, A. Jones, J. Peppe, D.M. Ross, H.Y.J. Rienhoff, HemaSphere 3 (2019) 369-370.

[3] J.C. Kauer, R.A. Carboni, J. Am. Chem. Soc. 89 (1967) 2633-2637.

[4] L.-Y. Wu, Y.-X. Xie, Z.-S. Chen, Y.-N. Niu, Y.-M. Liang, Synlett 9 (2009) 14531456.

[5] R.J. Lewis, N.I. Sax, Sax's Dangerous Properties of Industrial Materials, Van Nostrand Reinhold, New York, 1992.

[6] S. Mannan, in Lees' Loss Prevention in the Process Industries (Fourth Edition), Butterworth-Heinemann, Oxford, 2012, DOI: 10.1016/B978-0-12-3971890.00011-2, pp. 443-508.

[7] J.T. Fletcher, S.E. Walz, M.E. Keeney, Tetrahedron Lett. 49 (2008) 7030-7032.

[8] Y. Jiang, C. Kuang, Q. Yang, Synlett 9 (2009) 3163-3166.

[9] Y. Liu, C. Han, X. Ma, J. Yang, X. Feng, Y. Jiang, Tetrahedron Lett. 59 (2018) 650 653.
[10] M. Xu, C. Kuang, Z. Wang, Q. Yang, Y. Jiang, Synthesis 2 (2011) 223-228.

[11] M.-C. Giel, C.J. Smedley, E.R.R. Mackie, T. Guo, J. Dong, T.P. Soares da Costa, J.E. Moses, Angew. Chem. Int. Ed. 59 (2020) 1181-1186.

[12] M. Taillefer, N. Xia, A. Ouali, Angew. Chem. Int. Ed. 46 (2007) 934-936.

[13] S.W. Kwok, J.E. Hein, V.V. Fokin, K.B. Sharpless, Heterocycles 76 (2008) $1141-$ 1154.

[14] K. Sakai, N. Hida, K. Kondo, Bull. Chem. Soc. Jpn. 59 (1986) 179-183.

[15] S.S. van Berkel, S. Brauch, L. Gabriel, M. Henze, S. Stark, D. Vasilev, L.A. Wessjohann, M. Abbas, B. Westermann, Angew. Chem. Int. Ed. 51 (2012) 5343-5346.

[16] K. Harada, M. Oda, A. Matsushita, M. Shirai, Heterocycles 48 (1970) 695-702.

[17] I. P. Singh, P. Spevak, B. Palak, S. Amedjo, R. G. Micetich,

Economical Manufacturing Process for 1,2,3-triazoles, US005527920, 1996

[18] P.R. Clark, G.D. Williams, J.F. Hayes, N.C.O. Tomkinson, Angew. Chem. Int. Ed. 59 (6740-6744) (2020) 1.

[19] L.R. Zehnder, J.M. Hawkins, S.C. Sutton, Synlett 31 (2020) 175-178.

[20] Full consumption of p-toluene sulfonylhydrazide was observed by HPLC analysis of the reaction after $2 \mathrm{~h}$ at room temperature. The consumption of this peak coincided with the formation of a single new species which was consistent in mass with hydrazone 10 by LCMS analysis.

[21] R. Hanselmann, G.E. Job, G. Johnson, R. Lou, J.G. Martynow, M.M. Reeve, Org. Process. Res. Dev. 14 (2010) 152-158.

[22] The 72 hour time-point (Entry 7, Table 1) contained residual quantities of hydrazone 10, indicated by both HPLC and LCMS.

[23] The reason for the lower yields observed with aliphatic amines could be due to the increased basicity of an aliphatic amine when compared to an aromatic amine. Under the reaction conditions using acetic acid, the aliphatic amine will remained protonated, which would result in a lower concentration of free amine in the reaction mixture to participate in the desired transformation.

[24] A. E. Tapper, C. Celatka, A. G. Romero, J. M. McCall, T. Chancellor, J-X. Chen, X. Chen, H. Zhao, B. Biolatto, E. C. A. Brot, Z. Li, X. Liao, Methods and Processes for the Preparation of KDMIA Inhibitors, WO2018/035259, 2018.

[25] C.G.S. Lima, A. Ali, S.S. van Berkel, B. Westermann, M.W. Paixão, Chem. Comm. 51 (2015) 10784-10796. 